Association for Information Systems AIS Electronic Library (AISeL)

12-14-2009

\title{
Sacrificing the Holy Cows: A Firm-Level Study of Using Willingness-to-Cannibalize to Drive Innovative Software Project Management
}

Paul Christian Ward

University of Utah, chris.ward@business.utah.edu

Follow this and additional works at: http://aisel.aisnet.org/irwitpm2009

\section{Recommended Citation}

Ward, Paul Christian, "Sacrificing the Holy Cows: A Firm-Level Study of Using Willingness-to-Cannibalize to Drive Innovative Software Project Management" (2009). International Research Workshop on IT Project Management 2009. 6.

http://aisel.aisnet.org/irwitpm2009/6 


\title{
Sacrificing the Holy Cows: A Firm-Level Study of Using Willingness-to-Cannibalize to Drive Innovative Software Project Management
}

\author{
Paul Christian Ward \\ University of Utah, Salt Lake City, UT, USA \\ chris.ward@business.utah.edu
}

\author{
Paul Jen-Hwa Hu \\ University of Utah, Salt Lake City, UT, USA \\ actph@business.utah.edu
}

\begin{abstract}
Chih-Ping Wei
National Tsing Hua University, Hsinchu, Taiwan

cpwei@mx.nthu.edu.tw

\section{ABSTRACT}

Building on extant literature in innovation management and marketing, we develop a factor model for explaining firm value innovation that can be reflected in their systems project management. Our model focuses on value innovation and analyzes it from the aspect of willingness-to-cannibalize affected by firm size and inter-firm linkages. We highlight the mediating role of willingness-to-cannibalize that may reconcile the different views about the roles of firm size and inter-firm linkages in firm innovation. We test the model by conducting a survey involving 113 Taiwanese software firms. Our data show a good fit to the model and support all but two of the hypotheses it suggests. The model can explain a significant portion of the variance in value innovation as well as willingness-to-cannibalize. Our findings have several implications for systems project management that we also discuss.
\end{abstract}

\section{Keywords}

Software development, project management, firm size, inter-firm linkages, disruptive innovation, willingness-to-cannibalize, value innovation.

\section{INTRODUCTION}

Firms gain competitive advantage by resisting organizational inertia (Smith and Tushman, 2005) and thus must develop the ability to capitalize on serendipitous opportunities. Inflexible firms often have difficulty creating the organizational attitudes necessary for sustained competitive advantage (Silva and Hirschheim, 2007). In the Information Technology industry successful firms need to adopt flexible development strategies to implement systems projects, particularly those embracing significant risk tolerance and willingness-to-cannibalize. The need for flexibility and openness to change not only appears at the strategic level, but also needs to permeate the organization throughout. For sustainable long-term success, firms have to connect such strategic needs with systems project management practices.

We study, at a firm level, project management characteristics with a focus on value innovation (Kim and Mauborgne, 1997) and willingness-to-cannibalize (Chandy and Tellis, 1998). A firm-level innovative strategic perspective has direct implications for how systems development is implemented and managed at the project level. Herein, willingness-tocannibalize is an attitude guiding the project team throughout the project lifecycle; e.g., assessing whether to follow a common approach, continue to use existing methods/techniques, refine the project drastically, or abandon the project altogether. Value innovation is a strategic perspective and can foster a strong out-of-the-box, forward-looking perspective in firms' project management practices, as it helps the project team to decide, at the project onset, which projects should proceed and which projects are not worth pursuing, at least for now. Both willingness-to-cannibalize and value innovation have important effects on a firm's project management practices and its ability to lead the industry. Project management, as it is often practiced, places a significant focus on the need (or desire) for closure and staying within project parameters and goals in terms of time, cost, and scope. We suggest that such common practices can lead to diminished out-of-the-box thinking and innovative capability by firms. Tailoring the systems project management style to a value-innovative strategic orientation, through an attitude of willingness-to-cannibalize is mindful of the project manager's desire for closure, yet fosters the essential need to be creative. 
We examine firm-level systems development management in the Information Technology industry, striving to bridge two different views toward innovation. First, the role of firm size on firms' innovation ability to manage systems projects effectively has eluded consensus in previous studies; e.g., Ali (1994) versus Im, Dow and Grover (2001). We attempt to provide an analytical lens and empirical evidence for reconciling the inconsistent results regarding firm size. Second, we also address the inconclusive literature regarding the influences of inter-firm linkages on firms' value innovation. Several firmlevel studies have shown ambiguous influences of social ties on firm innovativeness; e.g., Hulsink, Elfring and Stam, (2008) versus Ahuja (2000). Conceptually, we analyze inter-firm linkages through the lens of bilateral agreements and non-exclusive partnerships (Goyal and Moraga-Gonzalez, 2001) and demonstrate how such analyses may help firms to better manage their external relations for fostering their willingness-to-cannibalize, ultimately leading to value innovation.

Extant literature offers little agreement toward the influences of firm size and inter-firm linkages on firms' value-innovation capability. The mixed results may suggest some mediating factors driving value innovations by firms. Building on the rich streams of literature in marketing and innovation management, we postulate that a firm's willingness-to-cannibalize in systems project management is an essential determinant of its value-innovation capability. According to our literature review, firms' engagement in value innovation are positively correlated with their willingness-to-cannibalize, that generally refers to how well a firm is prepared to reduce the actual or potential value of its investments to pursue a new innovation or opportunity (Chandy and Tellis, 1998). Willingness-to-cannibalize is important; it is an attitudinal trait of firms, premised in the culture of an organization. Empirical evidence suggests that established firms might be reluctant to let go of existing investments for pursuing a new innovation (Chandy and Tellis, 1998). Equipped with a better understanding of the important role of willingness-to-cannibalize, firms can assemble innovative systems development projects and manage them more effectively.

The remainder of this paper is organized as follows: In Section 2, we review relevant literature and describe our hypothesis development. Section 3 details our study design (including measurements, pretest, and targeted firms) and the data collection procedure. We report our data analyses and highlight some important results in Section 4. Our findings have several important implications that we discuss in Section 5. We conclude the paper in Section 6 with a summary and discussion of our study's contributions and limitations, and we point out some future research directions.

\section{THEORETICAL FOUNDATION AND HYPOTHESIS DEVELOPMENT}

Successful systems project management can be characterized as a process of managing with inferior task knowledge and implementing with inferior domain knowledge (Tiwana, 2009). Managing system development projects in such fluid environments is challenging. In the Information Technology industry, the characteristics of a firm's project management style are essential for initiating and successfully executing an innovative project. Organizational factors can affect project management style and effectiveness in distinct but complementary ways. For example, inter-firm linkages (Goyal and Moraga-Gonzalez, 2001) offer a project team access to external resources, fresh ideas, or trusted feedback from experienced and respected peers. Willingness-to-cannibalize (Chandy and Tellis, 1998) brings critical unsentimentality towards what has already been implemented, with an attitude of "does this really work for this context?" and an ability to take chances on something forward-looking. Value innovation embraces both inter-firm linkages and willingness-to-cannibalize (Kim and Mauborgne, 1997) as it fosters a strong out-of-the-box, forward-looking perspective in the firm's project management practices through access to external resources and risk tolerance

The literature on R\&D inter-firm collaborations seems to emphasize two distinct features: bilateral agreements and nonexclusive partnerships (Goyal and Moraga-Gonzalez, 2001). Bilateral agreements refers to the characteristics of the relationship between two agents in an inter-firm collaboration network, whereas non-exclusive partnerships allows firms to act as intermediaries. The importance of R\&D inter-firm collaborations has been extended into systems development (Cloodt, Hagedoorn and Roijakkers, 2007). There is a rather broad literature examining the impact of inter-firm collaboration on firm innovation; these networks provide firms with access to valuable external resources and other strategic advantages (see, for example, Goyal and Moraga-Gonzalez (2001) for a comprehensive survey). Prior research has identified bilateral agreements and non-exclusive partnerships as two distinct structural features of R\&D networks. Bilateral agreements enable deep relations between firms and non-exclusive partnerships allow firms to interact at a less detailed level with a broader community. According to our literature review, bilateral agreements and non-exclusive partnerships seem orthogonal to one another. Finding an optimal mix of ties, thus, demands conceptual analyses and empirical testing. Firms can, and should, adjust their mix of industry links according to their prioritization of different value-innovative projects.

Prior economics and new product development research has shown an important link between R\&D spending (i.e. investment in R\&D inputs) and firm innovation and performance (Chao and Kavadias, 2009). We analyze firm innovative performance 
from a value-innovation perspective (Kim and Mauborgne, 1997). Because systems developments seem to exhibit increasing returns to scale, microeconomic theory suggests $R \& D$ resource usage to moderate the positive effect on firms' valueinnovative performance (Cloodt, et al., 2007).

\section{Willingness-to-cannibalize and value innovation}

We define willingness-to-cannibalize as the extent to which a firm is willing to give up existing investments-product, service, or intellectual capital - in order to embrace the new (Chandy and Tellis, 1998). It is a crucial firm characteristic, manifested by a propensity for risk tolerance. Prior research has produced empirical evidence suggesting that established firms tend to be reluctant to let go of their existing investments for fostering new innovations (Chandy and Tellis, 1998). However, willingness-to-cannibalize has received little attention in prior research examining systems project management and firm innovation. We consider this factor crucial for firms competing in dynamic markets (e.g., Information Technology) and expect it to exhibit significant, positive effects on firms' value innovation through desirable flexibility and/or reduced organizational inertia. After all, if a firm does not make its own products/practices obsolete, its competitors will (Kim and Mauborgne, 1997) Therefore, we posit a positive association between willingness-to-cannibalize and a firm's value innovation and test the following hypothesis:

Hypothesis 1: A firm's willingness-to-cannibalize is positively associated with its value innovation.

\section{Firm size and willingness-to-cannibalize}

Much ado has been made about the relationship between firm size and firms' innovation ability. Although the rich research stream fails to reach a universal consensus, it converges around the role of firm size for firm innovation ability. Departing from prior research examining the direct impact of firm size, we suggest its influences to be mediated through the firm's willingness-to-cannibalize. In general, large-size firms tend to implement more standardized mechanisms and have a more bureaucratic structure than do their small and medium-sized counterparts. Such mechanisms and structures may confine a firm's willingness-to-cannibalize the existing practices, methods/techniques, or products/services. The posited mediation effect may partly explain the inconsistent results by previous research. Prior literature has examined firm size by measured by the number of full-time employees (Luttmer, 2007), sales volume, or asset value (Chandy and Tellis, 1998). Regardless of the measurement used, the prior research results consistently produce empirical evidence suggesting an important relationship between firm size and innovation ability (e.g., Chandy and Tellis 1998), usually negative rather than positive. Accordingly, we anticipate a negative association between firm size and willingness-to-cannibalize and test the following hypothesis:

Hypothesis 2: Firm size is negatively associated with a firm's willingness-to-cannibalize.

\section{Inter-firm linkages and willingness-to-cannibalize}

Prior research examining R\&D inter-firm collaborations seems to emphasize two distinct structural features of inter-firm linkages: bilateral agreements and non-exclusive partnerships (Goyal and Moraga-Gonzalez, 2001). Bilateral agreements, characteristics of the relationship between two agents in an inter-firm collaboration network, are determined by the nature, basis, and strength of the relationship (Goyal and Moraga-Gonzalez, 2001). As R\&D networks tend to be highly clustered (Cloodt et al., 2007), homophily - the tendency of like to bond with like-suggests that an agent with strong ties to another agent (e.g., one of its neighbor) is likely to have strong ties to many of its other neighbors. A social network consists of clusters of agents with strong ties, clusters of agents with weak ties, and/or few clusters with mixed ties. Prior research has shown the significant role of network clustering on a firm's ability to innovate (e.g., Koka and Prescott, 2008); several studies reexamine these results in the Information Technology industry; e.g., Cloodt et al. (2007). The collective findings seem to suggest positive effects of inter-firm linkage on firm innovation. We expect firms with greater inter-firm linkages to be more willing to cannibalize their existing practices, methods/techniques, and products/services. Lower relational embeddedness, manifested by a higher propensity for non-exclusive partnerships, allows a firm to act as intermediary between otherwise unconnected nodes in the network. In turn, this intermediary role allows firms to access more external resources and fresh ideas that further encourage and foster their willingness-to-cannibalize. The intermediary role can benefit firms if they are capable of maintaining the absorptive capacity for knowledge (Hanaki, Nakajima and Ogura, 2007). Widely connected firms with low relational embeddedness resemble mavericks that typically exhibit a lower threshold to change. We posit a positive relationship between inter-firm linkage and willingness-to-cannibalize and test the following hypothesis:

Hypothesis 3: Inter-firm linkages are positively associated with a firm's willingness-to-cannibalize. 


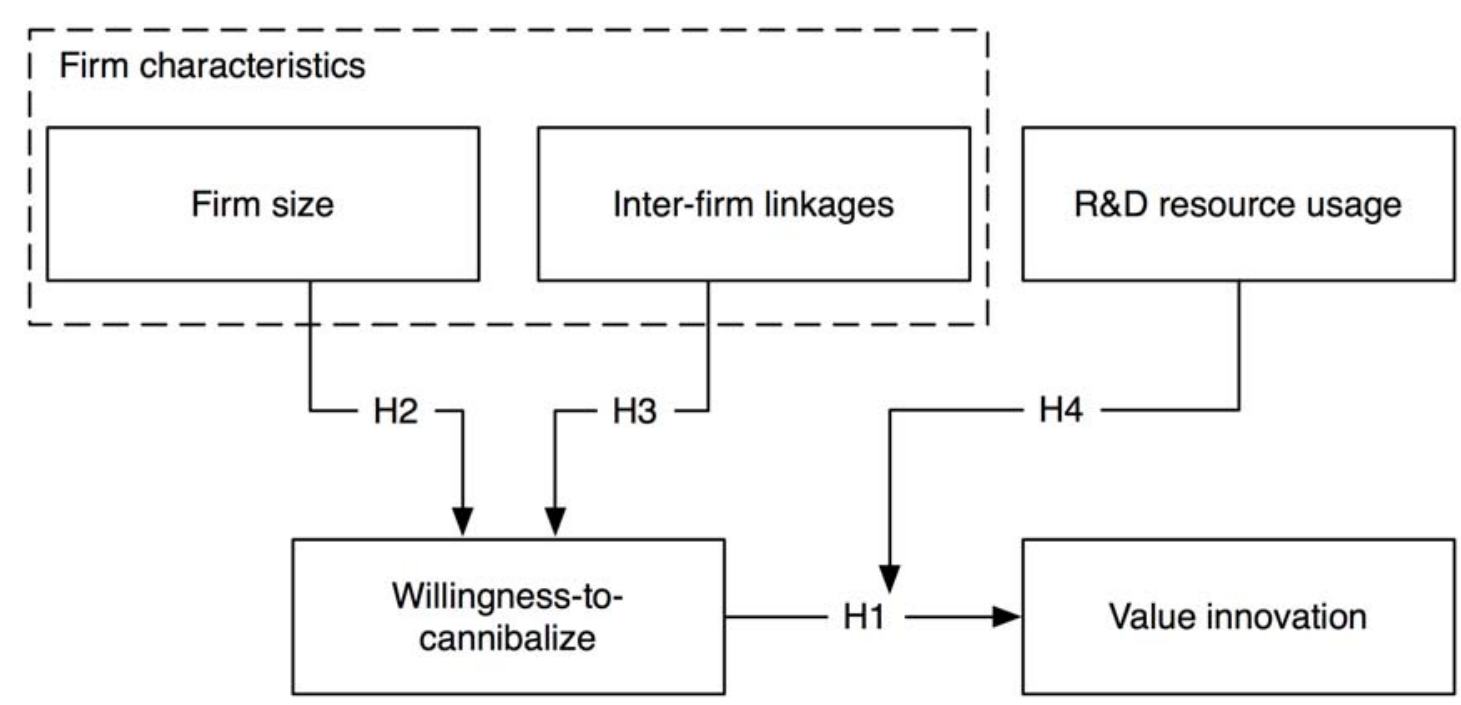

Figure 1: Research Model.

\section{Value innovation and firm performance}

Understanding the social context and important factors driving firm innovation, and ceteris paribus, what makes one firm excel at innovation while others may falter, can advance our understanding of firm innovations in the Information Technology industry as well as effective systems project management. Prior research has quantified firms' innovation ability in different ways; e.g., project management style from a strategic value-innovation perspective (Kim and Mauborgne, 1997) versus expenditures on software, hardware, and communications equipment (i.e. R\&D inputs) (Chao and Kavadias, 2009). Because of the increasing returns to scale of R\&D inputs in the software industry (Cloodt et al. 2007), we examine the moderating effect of $R \& D$ resource usage on firm value innovation. Hence, we expect the following:

Hypothesis 4: A firm's R\&D resource usage positively moderates the influence of willingness-to-cannibalize on a firm's value innovation.

Value innovation offers a viable measure of firm innovation ability (Kim and Mauborgne, 1997) and thus can affect firm performance directly. Value innovations often create new marketplaces or redefine market competition entirely (Kim, In, Baik, Kazman and Han, 2008), and thus likely will affect firm performance in a direct and significant way. In the Information Technology industry we can measure firm performance resulting from value innovation in terms of revenues and patent application filings (Bharadwaj, 2000); the latter of which is particularly important as they offer a tangible, quantifiable measure of the performance generated by the firm's innovation ability. Although not included in our structural model, we expect a positive relationship between value innovation and firm performance and therefore test the following hypothesis:

Hypothesis 5: A firm's value innovation is positively associated with firm performance.

According to our model (shown in Figure 1), value innovation is affected by willingness-to-cannibalize, which is determined by firm size and inter-firm linkage. In addition, our model also suggests R\&D resource usage moderates the influences of willingness-to-cannibalize on value innovation.

\section{STUDY DESIGN AND DATA COLLECTION}

To test our model and the hypotheses it suggests, we conducted a survey study involving 113 software firms in Taiwan. In this section, we describe our measurements, pretest, targeted firms, and data collection.

\section{Measurements}

The investigated constructs (i.e., factors) were mostly operationalized using items adapted from previously developed scales. Specifically, we measured willingness-to-cannibalize using items from Chandy and Tellis (1998); value innovation using 
items from Kim and Maborgne (1997); R\&D resource usage from U.S. Census Bureau (2009). We measured inter-firm linkage using items adapted from Ahuja (2000). Specifically, we establish and analyze a typography of bilateral agreements

\begin{tabular}{|c|c|c|c|c|c|c|c|}
\hline \multicolumn{4}{|c|}{ Characteristics of Respondents } & \multicolumn{4}{|c|}{ Characteristics of Participating Firms } \\
\hline \multicolumn{2}{|c|}{ Job title (pct.) } & \multicolumn{2}{|c|}{ Experience (yrs) } & \multicolumn{2}{|c|}{$\begin{array}{l}\text { Firm size (full-time } \\
\text { employees) (pct.) }\end{array}$} & \multicolumn{2}{|c|}{$\begin{array}{c}\text { Comparative size of software development } \\
\text { unit compared to peers (pct.) }\end{array}$} \\
\hline Project mgr. & 11.0 & 10th pctl. & 3 & $0-50$ & 66.37 & Very small & 14.16 \\
\hline Tech. lead & 6.5 & 25 th " & 6 & $51-100$ & 12.39 & Small & 30.97 \\
\hline Softw. engr. & 12.0 & 50th " & 10 & $101-150$ & 3.54 & Average & 38.05 \\
\hline Dev. dir. & 34.0 & 75th " & 15 & $151-200$ & 2.65 & Large & 11.50 \\
\hline CTO, etc. & 36.2 & 90th " & 20 & $>200$ & 15.05 & Very large & 5.31 \\
\hline
\end{tabular}

Table 1: Important Characteristics of Participating Firms and Respondents

that range from joint venture (strong collaboration) to technology sharing agreement (weak collaboration). We measured nonexclusive partnerships in a similar manner; i.e., by examining the extent to which a firm participated in more informal industry events such as trade associations and trade shows. Firm performance was measured on the basis of total revenue, the number of technology-related patent applications, and the number of technology-related copyrights, consistent with the items used by Luttmer (2007), Chandy and Tellis (1998), and Chao and Kavadias (2009). We assessed firm performance across three years (i.e., annually between 2005 and 2007) and thus can reduce the concerns about the time lag between innovative activities and their effects on firm performance. Each item employed a seven-point Likert scale.

\section{Pretest}

Our initial instrument consisted of 42 items. A panel of three domain experts, established researchers and seasoned practitioners, examined these items' validity at face value. This pretest led to the removal of seven items for network structure. The remaining items were then assessed by 15 graduate students experienced in Information Technology and systems project management, using an item-sort task method that allows us to verify whether a measurement item reflects the underlying latent construct, hereby establishing construct validity (Nunnally and Bernstein, 1978). We used the sorting outcomes by the respondents to examine construct validity and the results are satisfactory, suggesting our items exhibit adequate validity.

\section{Targeted Firms}

We targeted a broad section of Taiwanese software firms, in particular those in the 1987 Standard Industrial Classification (SIC) code 737; i.e., Computer Programming, Data Processing, and Other Computer Related Services (Occupational Safety \& Health Administration, 1987). We focused on these firms because of their importance in driving the global Information Technology industry and the need for value innovation reflected in systems project management practices. We conducted translation and back-translation of the survey to ensure the survey - to be distributed to firms in traditional Chinese-was identical to the survey in English. We made several minor wording changes according to the translation and back-translation results.

\section{Data Collection}

We took a key informant approach, targeting a key informant of each prospect firm. Overall, we targeted experienced software development professionals with at least two years of experience working in the firm and job functions in software development related areas. That is, our informants were individuals who currently, or had recently (within the last 1-2 years) worked in an important technical capacity; e.g., technical lead, software engineer, chief technology officer. We did not target business analysts or managers (e.g., marketing managers) because they typically have some general knowledge about the software development projects at the firm level but lack the technical knowledge necessary for completing our survey.

With the assistance of a professional survey company specializing in the Information Technology sector, we contacted 201 firms from the Information Service Industry Association of Taiwan, via telephone. Among them, 120 voluntarily agreed to participate in the study and attempted to complete the telephone survey. Seven of these firms provided partially complete responses, and their responses therefore were removed from our subsequent analyses. As a result, our sample consists of 113 
firms, showing an effective response rate of $56.2 \%$. We extrapolated from the number of firms listed on the Taiwan Stock Exchange categorized to our target firm category (as of July 2009). The overall population size is estimated to be approximately 300 firms, suggesting our study has a population response rate of $37 \%$. As shown in Table $1,30 \%$ of the respondents were project managers and the remaining held executive positions in different technical areas. The median experience level was 10 years and $85 \%$ of the respondents were male. $65 \%$ of the participating firms were small (i.e., less than 50 full-time employees) and $40 \%$ of the firms were established, $20 \%$ medium-sized, and $25 \%$ start-ups.

\section{ANALYSIS AND RESULTS}

We examined non-response bias by comparing our sample with the population in terms of firm size measured by total revenue and number of full-time employees. Our sample is representative of the overall population, as suggested by an insignificant between-groups difference $(p$-value $<0.10)$. We also compared early and late respondents; i.e., firms completing the survey during the first week versus those completed in the last week of our data collection. Again, these two groups are comparable $(p$-value $<0.10)$ in terms of total revenues and the number of full-time employee. Together, our results suggest that non-response bias does not appear to be a serious concern. Additionally, the distribution of the firm size in our sample follows a Pareto distribution, a finding consistent with those reported by prior studies (Luttmer, 2007).

We assessed the internal consistency of our instrument on the basis of Cronbach alpha. All constructs exhibit a Cronbach alpha value higher than the recommended threshold of 0.7 (Nunnally and Bernstein, 1978). We examined the instrument's convergent and discriminant validity by performing exploratory factor analysis (EFA) with principal components factor extraction and promax rotation, partly because not all of our items are adapted from previously validated scales. We used oblique rotation because it is not reasonable to assume the factors in the model completely independent; hence orthogonal rotation may not be appropriate. After conducting a scree test and parallel analysis (Preacher and MacCallum, 2003), five factors were retained. According to our result, the proposed factor model seems to capture the underlying structure of the data well (variance explained $=73.56 \%$ ). We further evaluated the convergent and divergent validity by examining the correlation cross-loadings between each construct's composite score and the indicator variables for the other constructs. All items load substantially higher on their own construct than on any other constructs (shown in Table A3).

We used partial least squares (PLS) modeling to examine the full research model. PLS was chosen because it requires fewer statistical specifications and constraints on the data than the covariance-based strategy of SEM (e.g., assumptions of normality) and it is generally more suitable when the phenomenon under study is new or changing (i.e. the theoretical framework is still in flux) (Chin, 1998). We tested our research model using Smart-PLS version 2.0 M3 (Ringle, Wende and Will, 2005). The guidelines by Chin, Marcolin and Newsted (1996) for modeling moderation effects were followed.

Although the measurement and structural parameters were estimated together, we interpreted the results in two stages: first assessing the structural model, and then examining the measurement model's reliability and validity. Standardized itemconstruct loadings were high $(>0.70)$ for all but seven items, all were significant at the 0.05 level except two items significant at the 0.10 level. We retained these items in the subsequent analysis for theoretical reasons. Each construct has consistent positive loadings, indicating the general convergence of the indicators to the respective constructs. Average variance extracted (AVE) and communality are essential indicators of the model's measurement fit. AVE ranged from 0.471 to 0.718 . Only one construct had AVE slightly below, but close to the recommended threshold of 0.50 (Gefen and Straub, 2005). The average communality coefficient is 0.59 , satisfactory in light of the common recommendation of a value greater than 0.30 (Gefen and Straub, 2005). Cronbach alpha for all constructs exceeded the recommended threshold of 0.70 (Nunnally and Bernstein, 1978); Composite reliability (CR) ranged from 0.77 to 0.91 , all of which were satisfactory with respect to the 0.70 recommended threshold (Gefen and Straub 2005). The model explains a significant portion of the variance in value innovation $\left(\mathrm{R}^{2}=0.36\right)$, and willingness-to-cannibalize $\left(\mathrm{R}^{2}=0.16\right)$, which were both greater than the recommended 0.10 (Falk and Miller, 1992). In the appendix, we provide some details of our measurement and structural model analysis results.

We examined the statistical significance of the loadings and the path coefficient estimates using a bootstrapping resampling method with 1000 resamples. Although the path coefficient estimates are below the recommended 0.70 level for confirmatory analysis, they seem to be in an acceptable range for exploratory analysis (Chin, 1998); all are statistically significant at the 0.05 level except for the path coefficient between firm size and willingness-to-cannibalize. To assess H5, we examined the correlation between value innovation and firm performance and noted a $95 \%$ confidence interval correlation coefficient ranging from 0.09 to 0.43 , statistically significant; $\mathrm{r}=0.266, \mathrm{t}(112)=2.278$, $p$-value $<0.05$. 
A minimum sample size required for medium effect size $\left(f^{2}=0.15\right)$ for our model with adequate power level (power $\left.=0.8\right)$ is 85 (Cohen, 1988), which we exceeded. Figure A2 in the Appendix explores the robustness of these findings. Specifically, we

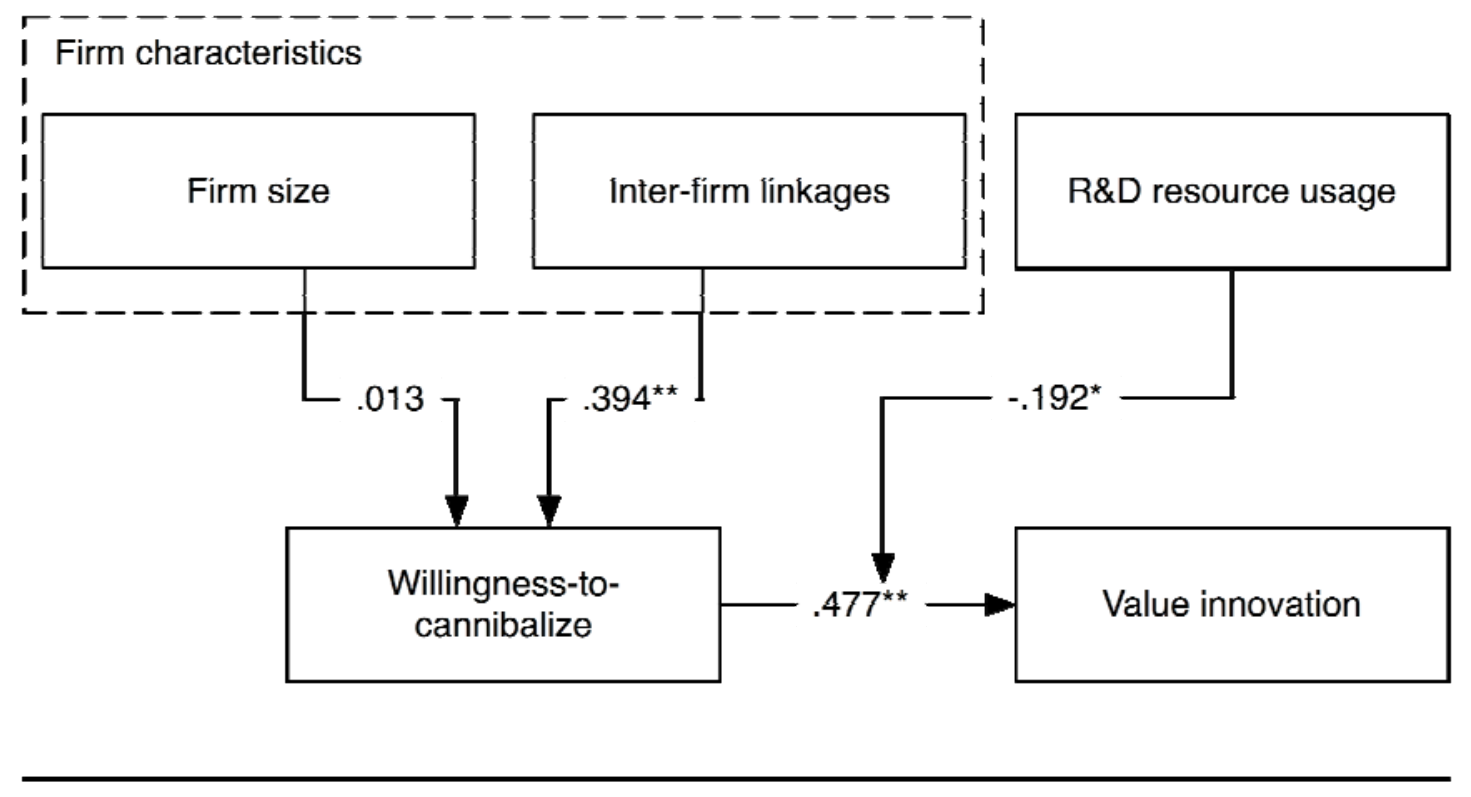

* pralue $<0.05$

- p-value $<0.001$

Figure 2: Research model with hypothesis testing results.

examined the robustness of our hypothesis testing results on the basis of different magnitude and statistical significance of the corresponding path in the model. We summarize our hypothesis testing results in Table 1 and Figure 2.

\section{DISCUSSION}

Overall, our data shows a good fit to the model and supports all its hypotheses except H2 and H4. Our findings have several implications for systems project management. We demonstrate the viability of anchoring systems project management to willingness-to-cannibalize and value innovation, and examine project management in perspective of firm innovation in the Information Technology industry where breakthrough innovations and rapid product cycles become prominent industry characteristics.

There are several implications from our study. First, for systems development project managers, our findings suggest the importance of fostering a culture of transparency and a need for the ability of the project team to be allowed to question all key aspects of the project. Willingness-to-cannibalize embodies a structured playfulness at the team level. Our findings highlight the need for project managers to pay close attention to the structure and internal makeup of the project team. As Chandy and Tellis (1998) comment, small, autonomous teams, each consisting of people with diverse backgrounds and focusing on a particular goal, can foster an innovative project management culture. Organizations characterized by risk tolerance and unsentimentality towards the existing practices, methods/techniques, protocols, or products/services encourage and drive value innovation are better poised to take a value-innovative approach. We recognize that not all aspects of a system development project will be innovative, e.g. maintenance updates, bug fixes. However, firms striving for becoming effective value innovators should organize the systems project management style accordingly.

Second, the lack of support for $\mathrm{H} 2$ is interesting. According to our analysis results, firm size does not appear to be a significant, direct determinant of willingness-to-cannibalize. This finding suggests that some firms, in spite of their large size, can overcome organizational inertia when the firm uses project management practices that acknowledge the potential for organizational inertia to disrupt the innovative process, and actively strive to foster an openness to questioning every practice, product, and process (i.e. willingness-to-cannibalize). Furthermore, this finding implies that firm size might not be critical, particularly when firms have rich inter-firm linkages for accessing valuable external resources, ideas, or trusted feedback 
from respected peers. Nevertheless, our result may be biased by our sample; i.e., $65 \%$ of the firms in our sample are small in size. This plausible bias warrants further analyses and empirical examinations.

In line with the findings by Cloodt, et al. (2007) and Goyal and Moraga-Gonzalez (2001), we observe a significant, positive association between inter-firm linkages and willingness-to-cannibalize. We demonstrate the feasibility of using the survey method to assess inter-firm linkages, wherein both bilateral agreements and non-exclusive partnerships seem to explain willingness-to-cannibalize. Our finding suggests that bilateral agreements allow firms to access a wider range of external resources, and that non-exclusive partnerships enable firms to connect to fresh ideas. Not only do these mechanisms have important implications for firm innovation, but also for project management. The project team can draw important resources, inspiration, and creativity from external influences, which thus should be encouraged. These mechanisms are important to firm innovation and deserve continued investigations.

Somewhat surprising is our data not supporting H4, as our literature review suggests R\&D resource usage to positively moderate the influence of willingness-to-cannibalize on value innovation. We note a negative moderating effect, rather than the hypothesized positive effect. This finding might be partly masked by our measurement of R\&D resource usage that has the lowest AVE among all the investigated constructs, and slightly below the recommended 0.5 threshold. It may also indicate that merely flooding a project with any and all resources isn't going to help the team implement the project any better. Nonetheless, we believe having access to the necessary tools is important for the project team if the systems implementation is to be successful. Last but not least, our data support H5, consistent with the prior research results. Judged by its significant effects on firm performance, value innovation is essential in the Information Technology industry and should reflect in system project management.

\section{CONCLUSION}

This study makes two main contributions to the project management literature. We first establish the moderating effect of willingness-to-cannibalize on value innovation, which suggests the need for systems development firms to use a flexible project management style embracing risk tolerance and out-of-the-box thinking. Second, we show the importance of a valueinnovative project management culture for successfully implementing cutting-edge systems projects. Understanding and fostering such a culture can have significant impacts on the software developer's bottom line.

Our study has several limitations to be addressed in our future research. First, in this study, we did not control for the absorptive capacity for new information with respect to non-exclusive partnerships. This factor needs to be considered in the design of future studies when examining the role of inter-firm linkages on firms' value-innovative ability. Second, a better measure of firm size is needed. When using a quantitative measure for firm size, larger firms, as measured by that term, will likely see higher innovative output by default. Controlling for this circularity by using a standardized measure for firm size is important for our future research. Third, it is important to further examine the respective impacts of value innovation and willingness-to-cannibalize on firm performance empirically, preferably with firms in different industries and geographic locations. Finally, although sample size is adequate, testing the model with a larger sample of firms, and investigating why path loadings were somewhat low should be priorities for future work.

\section{REFERENCES}

Ali, A. (1994) Pioneering versus incremental innovation: review and research propositions, Journal of Product Innovation Management, 11, 1, 46-61.

Ahuja, G. (2000) Collaboration networks, structural holes, and innovation: a longitudinal study, Administrative Science Quarterly, 45, 3, 425-455.

Bharadwaj, A. S. (2000) A resource-based perspective on information technology capability and firm performance: an empirical investigation, MIS Quarterly, 24, 1, 169-196.

Chandy, R. K., and Tellis, G. J. (1998) Organizing for radical product innovation: the overlooked role of willingness-tocannibalize, Journal of Marketing Research, 35, 4, 474-487.

Chin, W. W., Marcolin, B. L., and Newsted, P. R. (1996) A Partial Least Squares Latent Variable Modeling Approach for Measuring Interaction Effects: Results from a Monte Carlo Simulation Study and Voice Mail Emotion/Adoption Study, in J. I. DeGross, S. Jarvenpaa, and A. Srinivasan (Eds.) Proceedings of the Seventeenth International Conference on Information Systems, December 16-18, Cleveland, OH, USA, 21-41.

Chin, W. W. (1998) Issues and opinion on structural equation modeling, MIS Quarterly, 22, 1, 7-16.

Cloodt, M., Hagedoorn, J., and Roijakkers, N. (2007) Inter-firm R\&D networks in the global software industry: An overview of major trends and patterns. Working paper, Maastricht University, The Netherlands. 
Cohen, J. (1988) Statistical power analysis for the behavioral sciences, Erlbaum, Hillsdale, NJ, USA.

Falk, R. F. and Miller, N. B. (1992) A primer for soft modeling, University of Akron Press, Akron, OH, USA.

Gefen, D. and Straub, D. (2005) A practical guide to factorial validity using PLS-Graph: Tutorial and annotated example, Communications of AIS, 16, 91-109.

Goyal, S. and Moraga-Gonzalez, J. L. (2001) R\&D networks, RAND Journal of Economics, 32, 4, 686-707.

Hanaki, N., Nakajima, R. and Ogura, Y. (2007) The Dynamics of R\&D Collaboration in the IT Industry, Working Paper Series, SSRN eLibrary (http://ssrn.com/paper=1000103)

Hulsink, W., Elfring, T. and Stam, W. (2008) The locus of innovation in small and medium-sized firms: The importance of social capital and networking in innovative entrepreneurship, Working Paper Series, SSRN eLibrary (http://ssrn.com/paper=1290927)

Im, K. S., Dow, K. E. and Grover, V. (2001) Research report: a reexamination of IT investment and the market value of the firm - an event study methodology, Information Systems Research, 12, 1, 103-117.

Kim, S., In, H. P., Baik, J., Kazman, R. and Han, K. (2008) VIRE: sailing a blue ocean with value-innovative requirements, IEEE Software, 25, 1, 80-87.

Kim, W. C. and Mauborgne, R. (1997) Value innovation: the strategic logic of high growth, Harvard Business Review, 74, 1, 103-112.

Koka, B. R. and Prescott, J. E. (2008) Designing alliance networks: the influence of network position, environmental change, and strategy on firm performance, Strategic Management Journal, 29, 6, 639-661.

Luttmer, E. G. J. (2007) Selection, growth, and the size distribution of firms, Quarterly Journal of Economics, 122, 3, 11031144.

Nunnally, J. and Bernstein, I. H. (1978) Psychometric theory, McGraw Hill, New York.

Occupational Safety \& Health Administration (1987) SIC Manual. Available from http://www.osha.gov/oshstats/ (Online; accessed 02-Dec-2008, 19-Oct-2009)

Preacher, K. J. and MacCallum, R. C. (2003) Repairing Tom Swift's electric factor analysis machine, Understanding Statistics, 2, 1, 13-43.

Ringle, C. M., Wende, S. and Will, A. (2005) SmartPLS version 2.0 M3 (Software), University of Hamburg, Hamburg, Germany.

Silva, L. and Hirschheim, R. (2007) Fighting against windmills: Strategic information systems and organizational deep structures, MIS Quarterly, 31, 2, 327-354.

Smith, W. K. and Tushman, M. L. (2005) Managing Strategic Contradictions: a Top Management Model for Managing Innovation Streams, Organization Science, 16, 522-536.

Tiwana, A. (2009) Governance-knowledge fit in systems development projects, Information Systems Research, 20, 2, 180197.

U.S. Census Bureau (2009) 2007 Information and Communication Technology Survey, Available from http://www.census.gov/econ/ict/ (Online; accessed 02-Dec-2008, 19-Oct-2009) 
APPENDIX A: PLS MODEL

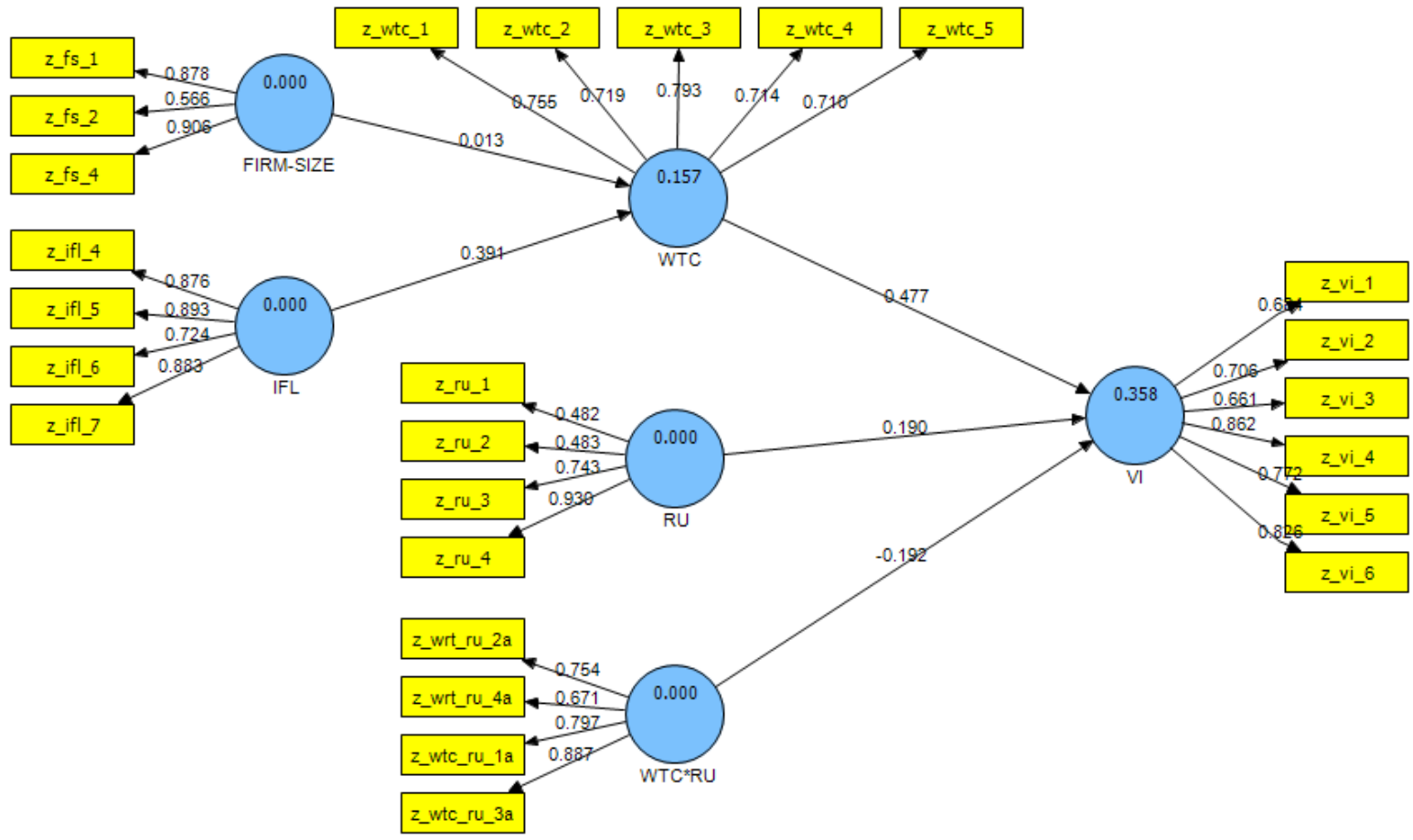

Figure A1: PLS path model.

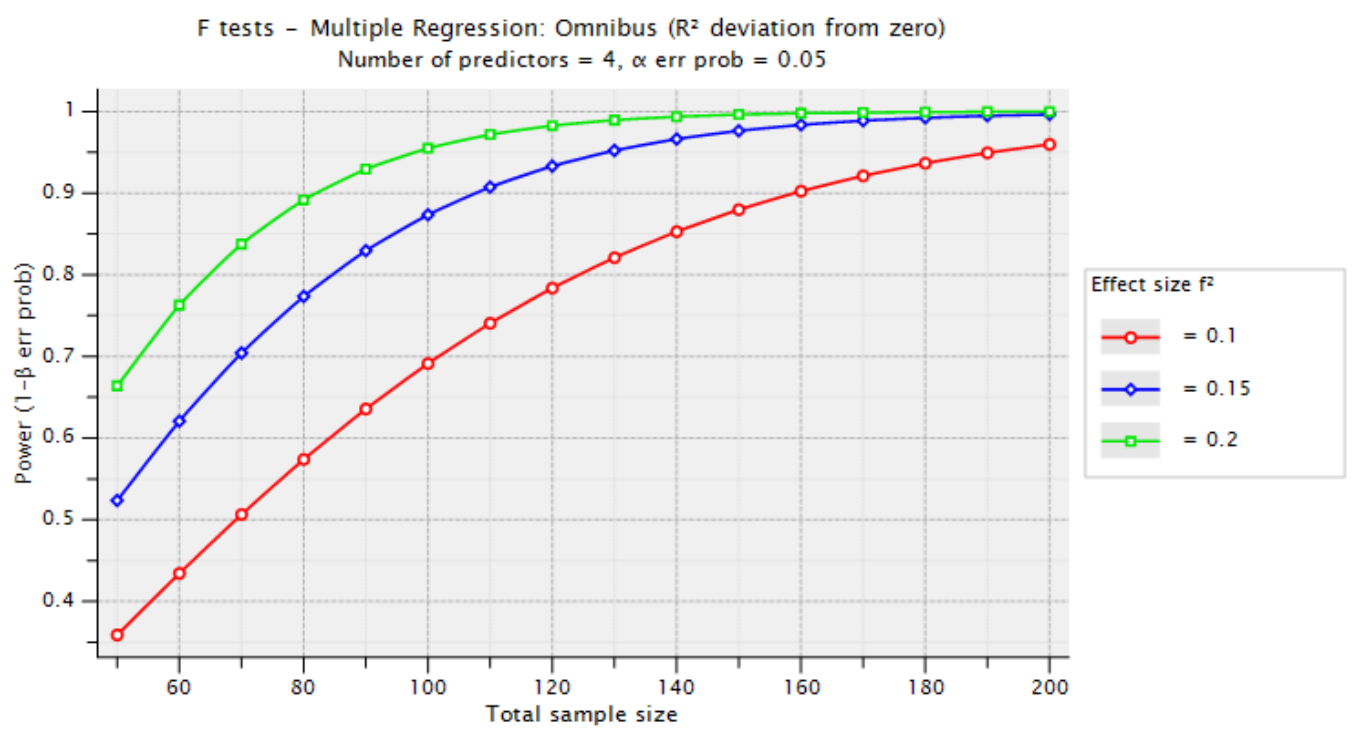

Figure A2: Model robustness. 


\begin{tabular}{|l|c|c|c|c|c|c||}
\hline & AVE & Composite Reliability & R Square & Cronbach Alpha & Communality & Redundancy \\
\hline \hline$F S$ & 0.6373 & 0.8354 & & 0.7807 & 0.6373 \\
\hline$I F L$ & 0.7175 & 0.9098 & & 0.8687 & 0.7175 \\
\hline$R U$ & 0.4707 & 0.7668 & & 0.7883 & 0.4707 & 0.5711 \\
\hline$V I$ & 0.5711 & 0.8878 & 0.3578 & 0.8487 & 0.0192 \\
\hline$W T C$ & 0.5462 & 0.8573 & 0.1566 & 0.7936 & 0.5462 & 0.0019 \\
\hline$W T C^{*} R U$ & 0.6102 & 0.8611 & & 0.7878 & 0.6102 \\
\hline
\end{tabular}

Table A1: Quality Criteria Summary.

\begin{tabular}{|l|c|c|c|c|c|c||}
\hline & FS & IFL & RU & VI & WTC & WTC*RU \\
\hline \hline$F S$ & 1.0000 & & & & \\
\hline$I F L$ & 0.3291 & 1.0000 & & & \\
\hline$R U$ & 0.3394 & 0.2271 & 1.0000 & & \\
\hline$V I$ & 0.1779 & 0.4093 & 0.1805 & 1.0000 & \\
\hline$W T C$ & 0.1415 & 0.3956 & 0.0453 & 0.5494 & 1.0000 & \\
\hline WTC*RU & -0.3480 & -0.3153 & 0.1592 & -0.3211 & -0.3336 & 1.0000 \\
\hline
\end{tabular}

Note: FS: firm size; IFL: inter-firm linkages; RU: R\&D resource usage; VI: value innovation; WTC: willingness-to-cannibalize

Table A2: Latent Variable Correlations. 


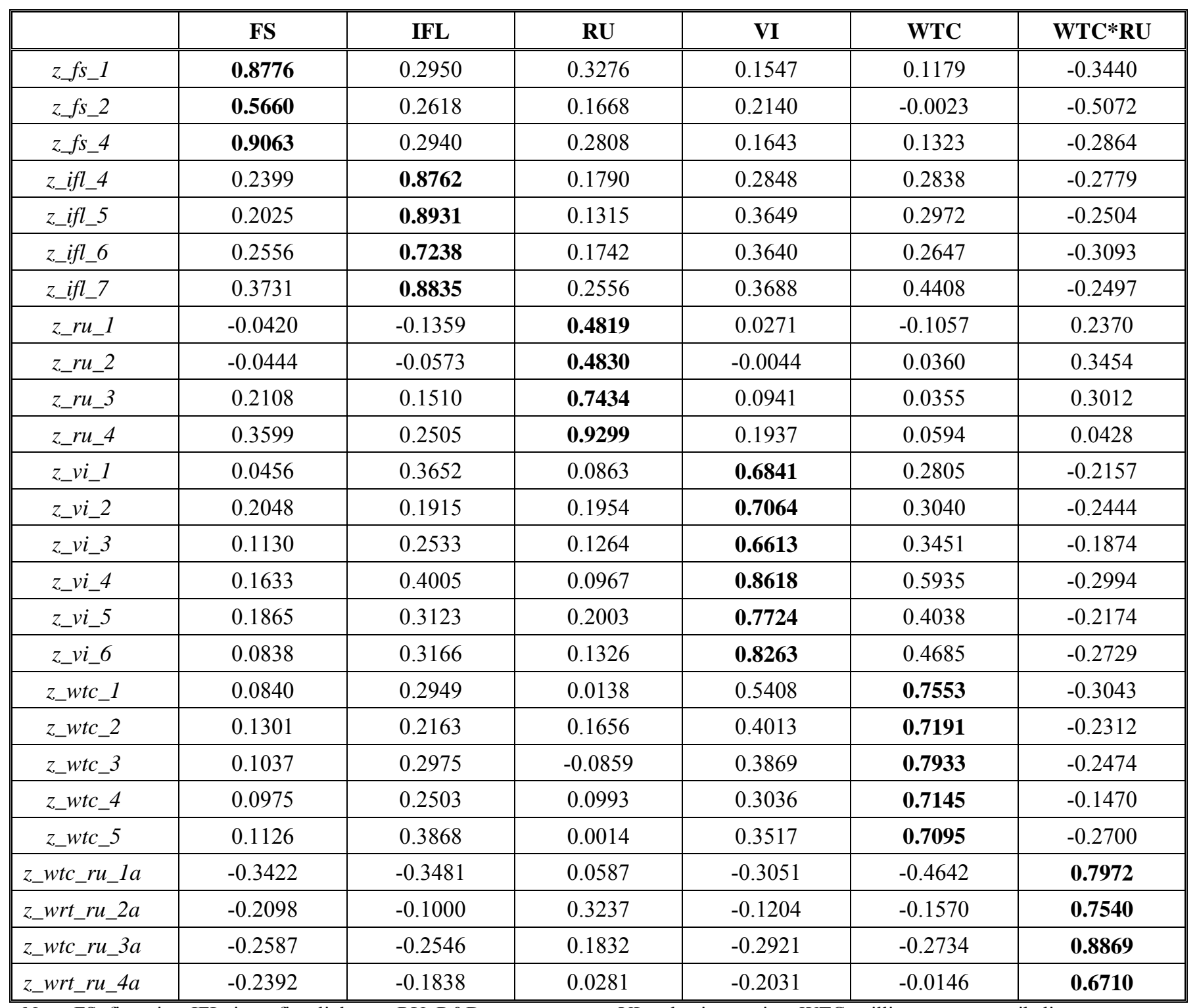

Note: FS: firm size; IFL: inter-firm linkages; RU: R\&D resource usage; VI: value innovation; WTC: willingness-to-cannibalize

Table A3: Cross-factor Loadings. 